\title{
Responsabilidade Socioambiental como Fator de Competitividade
}

\section{Socio-Environmental Responsibility as a Factor of Competitiveness}

\author{
Cristiane Paulino Gomes Gonçalves; Gilberto de Sousa Bruno ${ }^{\mathrm{b}}$; José Francisco dos Reis Neto*b; \\ Rafael Capriolli Gonçalves ${ }^{\mathrm{b}}$
}

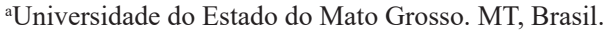 \\ Universidade Anhanguera Uniderp, Programa de Pos-Graduação Stricto Sensu em Produção e Gestão Agroindustrial. MS, Brasil. \\ *E-mail: gilberto.bruno@anhanguera.com
}

\begin{abstract}
Resumo
Este artigo visa avaliar como a responsabilidade socioambiental é um fator de competitividade para uma empresa do setor sucroalcooleiro instalada no Estado de Mato Grosso. O desenvolvimento foi embasado nas discussões sobre organizações no âmbito do setor sucroalcooleiro com foco na aplicação da responsabilidade socioambiental. A metodologia utilizada compreendeu o uso da técnica de pesquisa documental e bibliográfica aliada ao estudo de caso estruturado, a partir do cenário do setor sucroalcooleiro. Os resultados obtidos se referem como a responsabilidade socioambiental pode ser considerada um aspecto estratégico e um importante diferencial competitivo no mercado. Os projetos com foco na melhoria contínua do desempenho ambiental da empresa, como a adoção de praticas do seu papel de responsabilidade socioambiental que buscam contribuir para o crescimento e desenvolvimento das comunidades locais e regionais, a preservação do meio ambiente para a perpetuação da empresa, tornaram-se ainda mais credívéis perante aos stakeholders, os quais se mostram cada vez mais sensíveis e reativos às questões socioambientais.
\end{abstract}

Palavras-chave: Responsabilidade Socioambiental. Competitividade. Sucroalcooleira. Stakeholders.

\begin{abstract}
This article aims to evaluate how socio-environmental responsibility is a factor of competitiveness for a company from the sugar and alcohol industry installed in the State of Mato Grosso. The development was based on discussions on organizations within the scope of the sugar and alcohol sector with a focus on the application of social and environmental responsibility. The methodology used included the use of the documentary and bibliographic research technique allied to the structured case study, based on the scenario of the sugar and alcohol industry. The results obtained refer to how social and environmental responsibility can be considered a strategic aspect and an important competitive differential in the market. The projects focused on the continuous improvement of the company's environmental performance, such as the adoption of practices of its social and environmental responsibility that seek to contribute to the growth and development of local and regional communities, the preservation of the environment for the perpetuation of the company, have made even more credible vis-à-vis stakeholders, who are increasingly sensitive and reactive to social-environmental issues.
\end{abstract}

Keywords: Environmental Responsibility. Competitiveness. Sugar and Alcohol. Stakeholders.

\section{Introdução}

As organizações têm recentemente passado por uma profunda mudança na medida em que deixam de serem apenas organismos econômicos como afirmavam os teóricos da Administração Clássica, e passam a ocupar um papel sociopolítico. Segundo Mijatovic e Stokic (2010), a responsabilidade social corporativa representa uma forma de integração da atividade da empresa com o bem-estar social e questões ambientais. É neste novo cenário que surge a responsabilidade sociambiental das organizações bem como a necessidade de uma gestão dos impactos ambientais causados por seus processos produtivos.

D'Amato et al. (2009), afirma que as práticas socioambientais evoluíram de uma maneira muito intensa, passando de uma lógica pontual, que priorizava ações eventuais e assistencialistas, para uma visão integrada de desenvolvimento sustentável focado nos resultados, centrada nos públicos de interesse -stakeholders e, baseada no alinhamento estratégico mais consistente entre a empresa e sua missão.

O Brasil é o maior produtor de cana-de-açúcar do mundo, o País produziu mais de 624 milhões de toneladas de canade-açúcar na safra 2010. É também o $1^{\circ}$ produtor Mundial de açúcar, responsável por $25 \%$ da produção mundial e $50 \%$ das exportações mundiais. É o segundo produtor mundial de etanol, sendo responsável por $20 \%$ da produção mundial e $20 \%$ das exportações mundiais. O País tem uma estrutura produtiva com 441 unidades produtoras, 70 mil produtores de cana de açúcar, entre empregos diretos e indiretos gera 4,3 milhões postos de trabalhos, representa US\$ 14 bilhões das exportações e o PIB do setor ultrapassa os US\$ 29 bilhões (ÚNICA, 2018).

O Brasil é reconhecido mundialmente pelo forte componente renovável de sua matriz energética, hoje, mais de $47 \%$ de toda a energia utilizada no País vem de fontes renováveis, a cana-de-açúcar, matéria-prima para produção de 
etanol e bioeletricidade é a segunda maior fonte de energia do País, respondendo por $18 \%$ de toda a energia consumida pelo Brasil.

Segundo Michels e Arakaki (2012), a necessidade de se preservar o meio ambiente deixou de ser preocupação única de ambientalistas e de ONGs, e passou a ser de toda a humanidade. Fatores estes que levam consequentemente a variável ambiental a assumir um papel diferencial importantíssimo no quesito competitividade com o qual as empresas devem se preocupar.

Este artigo tem como objetivo demonstrar como a responsabilidade socioambiental gera um fator de competitividade para uma empresa sucroalcooleira situada no Estado de Mato Grosso. A investigação incide sobre uma empresa do setor sucroalcooleiro que tem destaque nacional em premiações de responsabilidade socioambiental, frente à comunidade em que está inserida e pela representatividade no mercado de açúcar, etanol e energia em Mato Grosso, que em capacidade de produção é a maior e detêm 37\% de todo o mercado, o que permitiu a concretização dos objetivos definidos.

\section{Desenvolvimento}

\subsection{Estudo de Caso}

\subsubsection{Empresa objeto de estudo}

A sede da empresa do setor sucroalcooleiro em questão e seu parque industrial localizam-se no Centro-Oeste do Brasil, na cidade de Nova Olímpia, Mato Grosso. Foi fundada no ano de 1980 e realizou sua primeira safra em 1983 com a produção de etanol e, em 1993 iniciou a produção de açúcar. A empresa também começou a produzir energia elétrica, a partir da biomassa da cana-de-açúcar, tornando-se autossuficiente. Em 2001 iniciou-se a comercialização do excedente de energia produzido para a concessionária Estadual - Rede ENERGISA - e a partir de 2007 ampliou sua capacidade, passando a produzir energia também na entressafra (periodo em que não se produz etanol e açúcar).

Em 2010 a Empresa moeu 5.128.441 toneladas de cana, o que correspondeu a $37 \%$ da cana moída no Estado de Mato Grosso. Com cerca de 3.500 empregos diretos, é responsável por $24 \%$ dos empregos do setor sucroalcooleiro do Estado de Mato Grosso. Em virtude de sua capacidade de produção e estocagem, mantém fornecimento constante de seus produtos, inclusive na entressafra. Atualmente é a maior unidade industrial sucroalcooleira do Estado de Mato Grosso e a quinta maior no ranking brasileiro, em virtude do seu potencial de capacidade produtiva instalada, geração de empregos e plantio de cana-de-açúcar.

No Quadro 1 é possível verificar a dimensão da estrutura da empresa.
Quadro 1 - Estrutura da empresa do setor sucroalcooleiro em questão

\begin{tabular}{|c|c|}
\hline Infraestrutura & Dimensões / Capacidades \\
\hline Terras próprias & 104.028 ha \\
\hline Terras cultiváveis & $\begin{array}{c}70.000 \text { ha (próprias e } \\
\text { arrendadas) }\end{array}$ \\
\hline $\begin{array}{l}\text { Potencial de produção de } \\
\text { cana-de-açúcar própria }\end{array}$ & 4.700 .000 toneladas/safra \\
\hline $\begin{array}{l}\text { Área sistematizada para } \\
\text { fertirrigação }\end{array}$ & 28.000 ha \\
\hline Frota & $\begin{array}{c}\text { Cerca de } 600 \text { equipamentos } \\
\text { motorizados }\end{array}$ \\
\hline Capacidade de moagem & $\begin{array}{l}6.300 .00 \text { toneladas em } 244 \\
\text { dias de safra }\end{array}$ \\
\hline Capacidade de produção & $\begin{array}{l}1500 \mathrm{~m}^{3} / \text { dia de etanol, } 2.000 \\
\text { ton./dia de açúcar e } 36 \mathrm{MW} / \mathrm{h} \\
\text { de energia elétrica, a partir da } \\
\text { biomassa }\end{array}$ \\
\hline Cogeração - Venda Externa & $\begin{array}{c}14 \mathrm{MW} / \mathrm{h} \text { de energia } \\
\text { elétrica, o suficiente para } \\
\text { abastecer uma cidade de } \\
\text { aproximadamente } 65.000 \\
\text { habitantes. }\end{array}$ \\
\hline
\end{tabular}

Fonte: Adaptado de Gonçalves (2013).

\subsection{Metodologia}

De acordo com Gil (2002), a técnica mais comum no estudo de caso é a análise documental e entrevistas semiestruturadas e/ou em profundidade. Nesse contexto, foi aplicado o estudo de caso, já que é uma técnica de recolha de dados a partir do objeto de estudo em análise. Com base no estudo realizado por Gonçalves (2013), o presente trabalho teve como objetivo verificar como a responsabilidade socioambiental pode ser um fator de competitividade para a "empresa do setor sucroalcooleiro em questão" situada em Mato Grosso.

No estudo em questão foi aplicada uma entrevisa semiestruturada ao gerente do Sistema de Gestão Ambiental, abordando os seguintes critérios: Infra-estrutura e Organização - avaliou as questões relativas a designação de um responsável pela área do meio ambiente, com foco no cumprimento das metas ambientais; Comprometimento com a responsabilidade socioambiental e Licenciamento ambiental no setor sucroalcooleiro - foco nas metas da política ambiental da empresa; Procedimentos - relativos aos impactos causados no meio ambiente por seus processos e produtos; Mobilização e Sensibilização - analisou como o empreendimento integra e se envolve com os stakeholders para cumprir as metas ambientais; Tecnologia - uso de tecnologias que podem ser adotadas como alternativas de solução visando à minimização de impactos ambientais; e, Vantagem Competitiva - examinou a vantagem competitiva da empresa, investindo na responsabilidade socioambiental e cumprido seu papel social. Assim, a seguir apresentam-se os procedimentos cumpridos para realização da entrevista com o representante da respectiva empresa do setor sucroalcooleiro em questão.

A empresa indicou o Gerente do Sistema de Gestão Ambiental como interlocutor na colaboração para esta 
investigação, a seguir marcou-se a data para realização da entrevista. No dia 06 de agosto de 2009, na sede administrativa da empresa, por mais de duas horas foi concedida uma entrevista com o Gerente, com vistas a obter informações gerais sobre a responsabilidade socioambiental da empresa. Assim, inicou-se uma longa explanação de como a empresa enfatiza a importância do desenvolvimento da responsabilidade socioambiental no mercado em que atua, expondo questões que enfocam a importância que a empresa dedica aos seus stakeholders, o relacionamento entre ambos e de como vem desenvolvendo seu papel social da preservação do meio ambiente, identificando como o mesmo poderia gerar diferencial competitivo para empresa, através de sua responsabilidade socioambiental.

Através de seu representante a empresa disponibilizou informações complementares que se demonstraram pertinentes para conclusão do trabalho. Em face disso foram transcritas as informações coletadas na entrevista, sendo enviadas ao entrevistado para confirmação com vista a garantir a fiabilidade das informações recolhidas.

Após a entrevista, seguidamente da compilação das informações recolhidas foi realizada uma analise dos dados para se chegar ao objetivo da pesquisa, relativamente às ações realizadas pela mesma a cerca da responsabilidade socioambiental e como a mesma pode se tornar um fator de competitividade para empresa, o que se justifica a caracterização da técnica de análise de dados a ser aplicada no estudo.

\subsection{Discussão}

Através da analise e discussão dos resultados obtidos com o estudo de caso realizado e a respectiva entrevista semiestruturada com o Gerente do Sistema de Gestão Ambiental da empresa, pode se verificar que a empresa apresenta os aspectos considerados mais relevantes, se adaptando as mudanças constantes e as exigências do setor sucroalcooleiro, sob a influência dos stakeholders e, por fim, tornando a responsabilidade socioambiental como um fator de competitividade.

A empresa se enquadra com grande diferencial competitivo, pois vem cada vez mais se adequando e adotando uma posição proativa com relação à responsabilidade socioambiental da empresa. Um dos aspectos a ser considerado é com relação à legislação aplicável às empresas do setor sucroalcooleiro, pois existem diversas exigências para essas empresas, relacionadas à preservação ambiental (proteção das áreas de preservação permanente, redução de queimada das palhas da cana-de-açúcar, redução de emições de gases do efeito estufa, controle da utilização de recursos hidricos, etc.). Constatou-se que não só cumpre com a legislação, como também supera em muito estas exigências, pois cumpre com um papel de responsabilidade socioambiental na execução de suas atividades inerentes a produção, como também, relacionado aos projetos que beneficiam seus stakeholders.
Dos aspectos positivos apontados pelo Gerente do Sistema de Gestão Ambiental, em relação à responsabilidade socioambiental e sua abrangência em toda a organização, que envolve seus stakeholder e gera fator de competitividade para imagem da empresa, podemos destacar:

- A empresa é responsável e vai além do cumprimento de seu papel na geração de riquezas pela produção de bens e serviços para a comunidade, com o objetivo de criar valor aos acionistas, pagar impostos, salários e outros benefícios aos seus colaboradores; desevolvendo sempre todas essas ações, primando pela ética e a transparência, respeitando as leis, o meio ambiente, o bem-estar da sociedade e a qualidade e eficiência, tanto dos produtos quanto das relações entre as partes envolvidas.

- A responsabilidade socioambiental é um fator de diferencial competitivo para a empresa do setor sucroalcooleiro, fato este comprovado através do estudo de caso realizado, como foi verificado face aos resultados apresentados, no qual é importante destacar o relato do entrevistado que: “A empresa que detém certificação ambiental se destaca, o que lhe atribui vantagem competitiva sobre as demais, caracterizada pela responsabilidade socioambiental e seu compromisso para com o meio ambiente, frente aos seus stakeholders. Um exemplo que podemos enfatizar, foi a exigência de um dos grandes clientes em que determinou um prazo de 18 meses para implementação da ISO 14.001 e, caso não o fizesse, a empresa do setor sucroalcooleiro em questão não poderia mais fornecer-lhes açúcar. Como já possuiam o Sistema de Gestão Ambiental implementado na empresa, o processo de certificação ocorreu dentro do programado. Esse cliente representa a venda de $60 \%$ de toda a produção de açúcar de uma safra, dessa forma, implica grande influência na tomada de decisão estratégica no ambito interno da organização e que enfatiza a importância da responsabilidade socioambiental, como vantagem competitiva no segmento sucroalcooleiro". A mesma ainda afirma, que "O compromisso com a responsabilidade socioambiental, transcende as fronteiras da empresa, enfocando a sua imagem, o que torna uma vantagem competitiva sobre as demais que a não possui. $\mathrm{O}$ compromisso assumido vem atender os requisitos impostos por grandes clientes, que tem os mesmos objetivos assumidos para com a responsabilidade socioambiental".

- O elevado grau de envolvimento da empresa com a responsabilidade socioambiental, em relação aos vários projetos sociais implementados junto as comunidades na qual está inserida (Projeto Canguro, Educação Financeira, De Bem Com Vida, Musica na Comunidade, Higiene Bucal Infantil, Estrelinha do Judô, Projeto Horta Amigos do Verde), como também, os projetos ambientais (Pensamos Verde, Madeira Legal, Um Mundo Mais Verde para as Crianças, Descartável e Belo, Muda Mundo, Reurbanização das Escolas, Preservar é Vida, Cidade Verde, Amiga do Parque Mãe Bonifácio, Doce Peixe, Ame a Arara, Agenda 21 e Implantação do Aterro Sanitário) evidenciam os requisitos de prioridade da empresa 
frente as questões socioambientais junto aos seus stakeholders. Esses são alguns dos projetos fomentados pela empresa do setor sucroalcooleiro em questão, que vem cada vez mais se aproximando da comunidade, procurando ampliar o bem-estar das pessoas que ali vivem, fazendo isso com grande respeito e cuidado com o meio ambiente.

- A aplicação constante de técnicas de monitoramento dos recursos naturais, em que uma equipe monitora as águas superficiais dos rios, córregos, lagoas e as águas subterrâneas, através de poços, para acompanhamento dos parâmetros químicos, físicos e biológicos, de forma que se mantenham a níveis aceitáveis, conforme estabelecido pelas leis ambientais em vigor, assim, priorizando o foco na preservação ambiental. Também cabe destacar, a coleta seletiva em toda unidade industrial e cidades vizinhas e destinação correta dos residuos gerados, uso de tecnologia de sistema de lavagem de gases para retenção de material particulado lançados na atmosfera e praticas de conservação solo.

- Geração de energia propria que atende as necessidades da empresa, tornando-a autossuficiente, sendo que o excedente é vendido para fornecimento a terceiros, o que representa mais uma fonte de renda e ganho em escala. A produção de energia elétrica, a partir da queima da biomassa da cana-de-açúcar, se traduz numa técnica de utilização de recurso natural renovável, considerada menos poluente que as obtidas a partir dos combustíveis fósseis, como petróleo e carvão mineral, além disso, permitindo o reaproveitamento do resíduo (biomassa da cana) industrial gerado.

- O reaproveitamento dos resíduos industriais, com foco na aplicação da adubação orgânica nas lavouras de canade-açúcar, possibilitando grandes reduções de custos, com a eliminação da compra de adubos químicos, resultando na "economia verde". Tachizawa e Pozo (2007), relatam em seus estudos que a atitude da empresa de investir em ações sociais e no desempenho ambiental da empresa, se traduz no reconhecimento público, como conseqüência, a empresa vira notícia, potencializa sua marca, reforça sua imagem, assegura a lealdade de seus empregados, fideliza clientes, reforça laços com parceiros, conquista novos clientes, aumenta sua participação no mercado, conquista novos mercados e incrementa suas vendas gerando vantagem competitiva para empresa.

- Um Sistema de Gestão Ambiental atuante, que define claramente e estabelece as ações preventivas e corretivas, que visam adotar medidas de controle e ações em caso de situações que não se adequam aos requisitos exigidos pela certificação ISO 14001, voltadas para com a Responsabilidade Social e a Qualidade Ambiental. Mijatovic e Stokic (2010), destacam a importância do Sistema de Gestão Ambiental, ISO 14001, como uma influência positiva no desenvolvimento das atividades de responsabilidade socioambiental da empresa.

A empresa desenvolve projetos sociais e ambientais sem qualquer cobrança, apenas para o bem-estar da comunidade e contribui para o seu crescimento, desenvolvimento e a preservação do meio ambiente. É importante destacar que para além de todos esses benefícios, através de suas ações de gerenciamento, a empresa destaca a minimização de custos obtidos na safra 2010/2011, conforme apresentado no Quadro 2.

Quadro 2 - Economia verde praticada pela empresa

\begin{tabular}{|c|c|c|}
\hline Ações & Quantidade & Economia \\
\hline $\begin{array}{c}\text { Redução do uso } \\
\text { de inseticidas no } \\
\text { controle de cupins ao } \\
\text { utilizar a metodologia } \\
\text { de praga de solo }\end{array}$ & $\begin{array}{c}\text { Redução de 903 kg } \\
\text { de inseticidas }\end{array}$ & US\$258.410,76 \\
\hline $\begin{array}{c}\text { Redução de adubação } \\
\text { química sólida, em } \\
\text { função da aplicação } \\
\text { do composto (torta } \\
\text { de filtro + cinza) no } \\
\text { sulco de plantio da } \\
\text { cana }\end{array}$ & $\begin{array}{c}\text { Redução da } \\
\text { quantidade de } \\
\text { fertilizantes sólidos } \\
\text { aplicados: } 108 \text { t de } \\
\text { Ureia, 360 t de Map } 17 \text { te KCL } \\
\text { e }\end{array}$ & US\$265.638,36 \\
\hline $\begin{array}{c}\text { Redução da adubação } \\
\text { química sólida, em } \\
\text { função da utilização } \\
\text { da fertirrigação } \\
\text { (vinhaça). }\end{array}$ & $\begin{array}{c}\text { Redução da } \\
\text { quantidade de } \\
\text { fertilizantes sólidos } \\
\text { aplicados: } 3.302 \mathrm{t} \\
\text { de KCL. }\end{array}$ & US\$1.654.739,90 \\
\hline $\begin{array}{c}\text { Redução da queima } \\
\text { da palha da cana-de- } \\
\text { açúcar, através da } \\
\text { colheita mecanizada }\end{array}$ & $\begin{array}{c}\text { Safra 2010/2011 } \\
-83 \% \text { de colheita } \\
\text { de cana crua (sem } \\
\text { utilização da } \\
\text { queima) }\end{array}$ & Benefícios \\
Ambientais \\
\hline
\end{tabular}

Fonte: Adaptado de Gonçalves (2013).

Nota-se que através das ações de gerenciamento ambiental a empresa, adiquiriu benefícios ambientais, incremento de mercado, redução de custos e vantagens competitivas através da sua responsabilidade socioambiental. Diante de todo o exposto pode-se considerar que a empresa estudada vem adotando políticas administrativas socioambientais corretamente, ultrapassando as obrigações impostas por Leis, sem abrir mão de sua lucratividade e tornando-se uma marca cada vez mais forte e competitiva.

\section{Conclusão}

Observa-se que o presente artigo relata que a responsabilidade socioambiental é bastante ampla, podendo destacar que a questão da responsabilidade social empresarial e ambiental diz respeito à postura legal da empresa significando uma mudança de atitude voltada para uma perspectiva de gestão empresarial com foco na qualidade da relação com a comunidade, geração de valores para todas envolvidos e preservação ambiental. Esta é centrada na análise de como as empresas interagem com o meio em que habitam e praticam suas atividades, mantendo uma política de responsabilidade socioambiental que garanta a preservação ambiental, melhoria da qualidade de vida, redução dos efeitos das mudanças climáticas globais, etc.

A melhoria continua do desempenho ambiental está presente constantemente no planejamento e execução das principais atividades desenvolvidas na empresa, adotando 
o uso de tecnologias que diminuem a degradação do meio ambiente e que visam obter benefícios ambientais através do gerenciamento adequado das atividades. No roteiro da entrevista, constatou-se, que os processos ambientais praticados pela empresa do setor sucroalcooleiro em questão, beneficiam a sociedade e o meio ambiente, oferecendo suporte à comunidade em que esta inserida, e trabalhando de forma sustentável, aliado a uma forte política de preservação ambiental. É importante destacar a relevância que a empresa do setor sucroalcooleiro em questão dá sobre o gerenciamento ambiental, utilizando de várias ações que auxiliam no processo estratégico de desenvolvimento de técnicas e procedimentos corretos, relacionados à minimização dos impactos causados ao meio ambiente.

Seu compromisso com a ética e transparência, para com os stakeholders é evidenciado através da publicação do Relatório de Sustentabilidade, que retrata todos os investimentos realizados em novas tecnologias para melhoria do seu desempenho ambiental, redução de custos mediante as praticas de reutilização de residuos industriais, contribuições sociais realizadas junto às comunidades em que esta inserida, destacando os projetos de cunho social e ambiental que envolve todas as partes interessadas de sua cadeia produtiva.

Em linhas gerais, considera-se que a responsabilidade socioambiental faz parte das prioridades da empresa do setor sucroalcooleiro em questão, da qual sabe gerenciar as ações ambientais, de forma adequada, o que contribui para o beneficio socioambiental como para o desenvolvimento sustentável, podendo assim sobreviver neste mercado altamente competitivo.

É importante salientar que a empresa desenvolve projetos sociais e ambientais sem qualquer cobrança legal, com foco em minimizar os impactos ambientais causados pelas atividades desempenhadas na região em que está inserida, retribuindo assim, para o bem-estar da comunidade (stakeholders), e contribuindo para o seu crescimento, desenvolvimento e a preservação do meio ambiente. Assim, podemos destacar que para além de todos esses benefícios, através de suas ações de gerenciamento da minização dos impactos ambientais, a empresa demonstra seus resultados com a redução de custos obtidos na safra 2010/2011 no valor de US\$ 2,178,788.90, como uma "Economia Verde". Nota-se que para através de suas ações a empresa do setor sucroalcooleiro em questão, adiquiriu benefícios ambientais, incremento de mercado, redução de custos e vantagens competitivas, através de sua atuação e comprometimento para com a responsabilidade socioambiental.

\section{Referências}

D 'AMATO, A; HENDERSON, S.; FLORENCE, S. Corporate Social responsibility and sustainable business a Guide to leadership tasks and functions. CCL Stock $n^{\circ} 355$ Center for Creative Leadershi. Greensboro, North Carolina, 2009.

GIL, A.C. Como elaborar projetos de pesquisa. São Paulo: Atlas, 2002.

GONÇALVES, C.P.G. Responsabilidade socioambiental como fator de competitividade: estudo de caso em uma empresa do setor sucroalcooleiro no brasil. Coimbra, PT, 2013.

JUNIOR, R.C.S. Estratégias competitivas do setor calçadista do Ceará. Lisboa: Instituto Universitário de Lisboa, 2010.

MICHELS, I.L.; ARAKAKI S.R.M. Setor sucroenergético brasileiro: os custos ambientais como fator de diferenciação. DELOS: Desarrollo Local Sostenible, v.5, n.15, 2012.

MIJATOVIC, I.S.; STOKIC, D. The influence of internal and external codes on csr practice: the case of companies operating in Serbia. J. Bus. Ethics, v.94, p.533-552, 2010.

TACHIZAWA, T.; POZO, H. As 100 melhores empresas em indicador de desenvolvimento humano organizacional - IDHO. Gestão \& RH, v.12, 2007.

ÚNICA - União da Indústria de Cana-de-açúcar. 2018. Disponível em: http://www.unicadata.com.br/ Acesso em: 15 maio 2019. 